\title{
Haematological changes after snake bite: a clinico-haematological study in a teaching hospital of South Bengal, India
}

\author{
Sumon Mondal ${ }^{1}$, *Bidyut Kumar Khuntdar ${ }^{2}$ \\ Sri Lanka Journal of Child Health, 2021; 50(1): 12-16
}

\begin{abstract}
Background: Snake bite can result in local as well as systemic manifestations. Major systemic complications include acute renal failure, neurological symptoms requiring ventilator support and coagulation disorders. The coagulation disorders lead to various serious systemic complications like haemorrhage, infarction and even death if the diagnosis and treatment are delayed.
\end{abstract}

Objectives: To describe the clinical profile of the snake bitten patients who developed coagulopathy and the role of coagulation markers to evaluate the morbidity and mortality of the victims.

Method: A cross-sectional hospital based study was done on patients aged 12 years or less having local or systemic signs of envenomation and no history of bleeding or coagulation disorders. The coagulation profile was assessed by peripheral blood sampling and urine analysis.

Results: In the present study haemorrhagic manifestations seen included bleeding from injection site $(46.7 \%)$, haematemesis $(5 \%)$, haematuria $(33.3 \%)$, bleeding gums $(11.7 \%)$, epistaxis (1.7\%), and haemoptysis (3.3\%). Haemoglobin estimation revealed anaemia in $53.3 \%$ cases. The 20 minute whole blood clotting time (WBCT20) was positive in $86.4 \%$ of vasculotoxic snakebites and negative in all neuro-paralytic bites. Leucocytosis was observed in $60 \%$ cases with relative neutrophilia in $63.3 \%$, thrombocytopenia was observed in $8.3 \%$, bleeding time was prolonged in $13.3 \%$ and clotting time was prolonged in $56.7 \%$.

${ }^{1}$ Junior Resident, ${ }^{2}$ Associate Professor, Department of Paediatrics, Midnapore Medical College, Midnapore, West Bengal, India.

*Correspondence: bkhuntdar1971@gmail.com

https://orcid.org/0000-0002-3453-0937

(Received on 03 January 2020: Accepted after revision on 28 February 2020)

The authors declare that there are no conflicts of interest

Personal funding was used for the project.

Open Access Article published under the Creative

Commons Attribution CC-BY (c) (i) License
Conclusions: WBCT 20 is an important test to differentiate between viperine and elapine bites as it was positive in $46.7 \%$ of viperine bites and was negative in all elapine bites

DOI: http://dx.doi.org/10.4038/sljch.v50i1.9395

(Keywords: snake bite, WBC count, bleeding time, clotting time, PT, APTT)

\section{Introduction}

In India, around 35,000-50,000 people die of snake bite annually ${ }^{1}$. Globally, around 3500 species of snakes have been identified, of which less than 350 are venomous ${ }^{2}$. Snake venom is one of the most complex toxins produced by plant or animal ${ }^{3}$. The principal toxins in snake venom are haematoxin, cytolysin, neurotoxin and cardiotoxin ${ }^{4}$. Snake venom also contains sodium, calcium, magnesium, zinc and iron ${ }^{5}$. Some snake venoms contain carbohydrates ${ }^{6}$. Elapid venoms are rich in acetyl cholinesterase, while crotalid and viperoid venoms are rich in endopeptidase ${ }^{7}$. Important enzymes in snake venom include proteolytic enzymes, thrombin-like enzymes, arginase ester hydrolase, collagenase, hyaluronidase, phospholipases, lactate dehydrogenase, phosphoesterases, acetylcholinesterase, RNase, DNase, 5'nucleotidase $^{8}$. As the elapid venom is mainly neurotoxic, common clinical manifestations are neuromuscular paralysis, ptosis, ophthalmoplegia and bulbar paralysis. In contrast, viper venom produces shock, haemorrhage and disseminated intravascular coagulation (DIC) ${ }^{9}$.

\section{Objectives}

To describe the clinical profile of the snake bitten patients who developed coagulopathy and the role of coagulation markers to evaluate the morbidity and mortality of the victims.

\section{Method}

A descriptive observational study was conducted in the paediatric wards of Midnapore Medical College and Hospital, West Bengal, India from May 2014 to April 2015. Detailed clinical examination was done in every case. To identify the nature of the snake bite (vasculotoxic, neuroparalytic, nonpoisonous) opinion was sought from the treating physician. Blood sample collection from each case was done aseptically for haematological investigations. Clotting time was assessed by Lee 
and White method ${ }^{10}$. Haematological investigations done immediately after clinical evaluation were 20minute whole blood clotting time, haemoglobin \%, total and differential white blood cell count, platelet count, red cell morphology, bleeding time, clotting time, prothrombin time and activated partial thromboplastin time. Subsequent information was collected on day of discharge or death of patient from the case notes.

Ethical issues: Ethical clearance was obtained from the Ethics Review Committee of Midnapore Medical College, Midnapore, West Bengal, India (ERC No. IEC/ MMC/78) on 15/01/2014. Written informed consent was obtained from the parents of the participating children

Statistical analysis: Data were entered into Microsoft Excel spread sheet and analysed. p-value was calculated by Fischer's exact test.

\section{Results}

The total number of admissions during the study period to the paediatric wards was 8204 of which $103(1.3 \%)$ were due to snake bite/unknown bite. Of the 103 , sixty $(0.7 \%)$ were due to poisonous snake bite and $43(0.5 \%)$ were due to nonpoisonous bites. Of the 60 patients included in the study, 37 (61.7\%) were males and 23 (38.3\%) were females giving a male: female ratio of 1.6. In the present study haemorrhagic manifestations seen were, bleeding from injection site (46.7\%), haematemesis $(5 \%)$, haematuria $(33.3 \%)$, bleeding gums $(11.7 \%)$, epistaxis $(1.7 \%)$, and haemoptysis $(3.3 \%)$. [Figure 1 ].

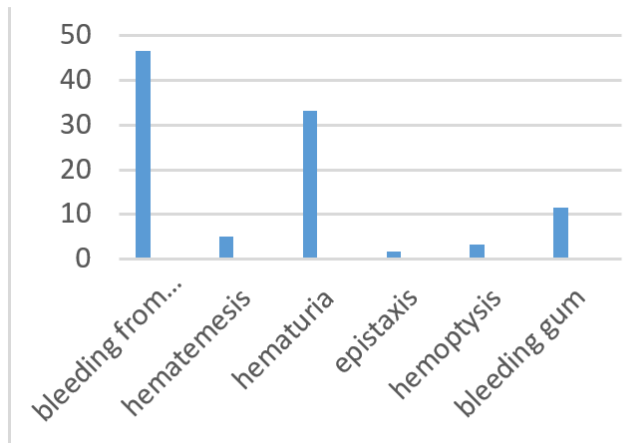

Figure 1: Case distribution based on bleeding manifestations
In the present study, neurological involvement was seen in $26.7 \%$ cases. Ptosis $(20 \%)$ was the most common feature followed by altered sensorium (15\%), dysarthria (8.3\%), ophthalmoplegia (8.3\%), respiratory paralysis $(3.3 \%)$ and convulsions $(1.7 \%)$ [Figure2]

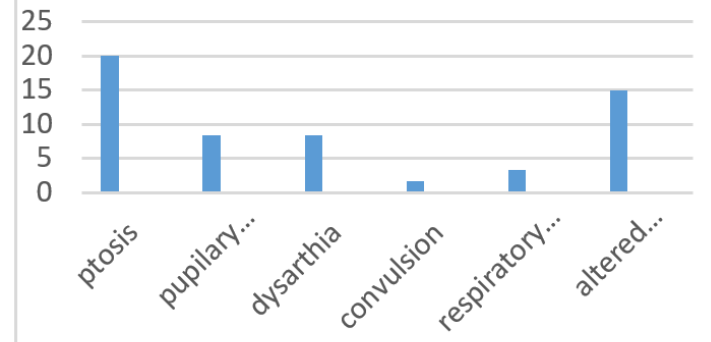

Figure 2: Case distribution based on neurologica manifestations

In the present study $5(8.3 \%)$ consulted traditional health care practitioner, $32 \quad(53.3 \%)$ reached primary health centre and $23(38.3 \%)$ reached tertiary hospital first after bite. The distribution of cases with anaemia and thrombocytopenia is shown in Table 1. The distribution of cases depending on the leucocyte counts is shown in Table 2. The distribution of cases depending on the 20 minute whole blood clotting time (WBCT20) with type of toxic symptoms is shown in Table 3. The distribution of cases depending on the WBCT20 with species of snake bite is shown in Table 4 . The distribution of cases based on variation in bleeding time/clotting time is shown in Table 5. The distribution of cases based on variation in prothrombin time and activated partial thromboplastin time is shown in Table 6.

Table 1: Distribution of cases with anaemia and thrombocytopenia

\begin{tabular}{|l|c|c|}
\hline \multicolumn{1}{|c|}{ Type of snake bite } & $\begin{array}{c}\text { Anaemia } \\
\text { Number (\%) }\end{array}$ & $\begin{array}{c}\text { Thrombocytopenia } \\
\text { Number (\%) }\end{array}$ \\
\hline Vasculo-toxic & $25(41.7)$ & $04(06.7)$ \\
\hline Neurotoxic & $07(11.7)$ & $01(01.7)$ \\
\hline Total & $32(53.4)$ & $05(08.4)$ \\
\hline
\end{tabular}


Table 2: Distribution of cases depending on the leucocyte counts

\begin{tabular}{|l|c|c|}
\hline \multicolumn{1}{|c|}{ Total leucocyte count } & Type of snake bite & Cases (\%) \\
\hline \multirow{2}{*}{ Less than $4000 / \mathrm{cu} \mathrm{mm}$} & Vasculo-toxic & $03(05.0)$ \\
\cline { 2 - 3 } & Neurotoxic & $02(03.3)$ \\
\hline \multirow{2}{*}{ Mo00-11,000/cu mm } & Vasculo-toxic & $11(18.3)$ \\
\cline { 2 - 3 } & Neurotoxic & $08(13.3)$ \\
\cline { 2 - 3 } & Vasculo-toxic & $28(46.7)$ \\
\cline { 2 - 3 } & Neurotoxic & $08(13.3)$ \\
\hline
\end{tabular}

Table 3: Distribution of cases depending on 20 minute whole blood clotting time with type of toxic symptoms

\begin{tabular}{|l|c|}
\hline \multicolumn{1}{|c|}{ Type of snake bite } & Cases (\%) \\
\hline Vasculo-toxic & $38(86.4)$ \\
\hline Neurotoxic & 0 \\
\hline
\end{tabular}

Table 4: Distribution of cases depending on 20 minute whole blood clotting time with species of snake bite

\begin{tabular}{|l|c|c|}
\hline 20 minute whole blood clotting time result & Viperine & Elapine \\
\hline Positive & $28(46.7 \%)$ & $0(0 \%)$ \\
\hline Negative & $16(26.7 \%)$ & $16(26.7 \%)$ \\
\hline
\end{tabular}

Table 5: Distribution of cases based on variation in bleeding time/clotting time (n-60)

\begin{tabular}{|l|c|c|c|c|}
\hline \multirow{2}{*}{ Type of snake bite } & \multicolumn{2}{|c|}{ Bleeding time } & \multicolumn{2}{c|}{ Clotting time } \\
\cline { 2 - 4 } & Normal & Prolonged & Normal & Prolonged \\
\hline Vasculo-toxic & $61.7 \%$ & $11.7 \%$ & $16.7 \%$ & $56.7 \%$ \\
\hline Neurotoxic & $25.0 \%$ & $01.7 \%$ & $26.7 \%$ & $0 \%$ \\
\hline Total & $86.7 \%$ & $13.4 \%$ & $43.4 \%$ & $56.7 \%$ \\
\hline
\end{tabular}

Table 6: Distribution of cases based on variation in prothrombin time and activated partial thromboplastin time (APTT) $(n=60)$

\begin{tabular}{|l|c|c|c|c|}
\hline \multirow{2}{*}{ Type of snake bite } & \multicolumn{2}{|c|}{ Prothrombin time } & \multicolumn{2}{c|}{ Activated partial thromboplastin time } \\
\cline { 2 - 5 } & Normal & Prolonged & Normal & Prolonged \\
\hline Vasculo-toxic & $36.7 \%$ & $36.7 \%$ & $40.0 \%$ & $33.3 \%$ \\
\hline Neurotoxic & $26.7 \%$ & $0 \%$ & $26.7 \%$ & $0 \%$ \\
\hline Total & $63.3 \%$ & $36.7 \%$ & $66.7 \%$ & $33.3 \%$ \\
\hline
\end{tabular}

Oliguria and renal type of oedema indicating acute renal failure were observed in $3.3 \%$ cases. In the present study, $61.7 \%$ of cases received $1-10$ vials, $36.7 \%$ cases $11-20$ vials and $1.7 \%$ cases $21-30$ vials of anti-snake venom (ASV). In the present study $10 \%$ of cases had pyrogenic reaction /urticarial. In the present study death due to vasculo-toxic and neuro-paralytic snakebites were $9.1 \%$ and $12.5 \%$ respectively. The overall mortality was $10 \%$. The $p$ value is 0.6 which is not significant. It indicates that viperine bites are not more lethal than elapine bites.

\section{Discussion}

Haemorrhagic symptoms were the most common presentation in the present study. These included bleeding from injection site $(46.7 \%)$, haematemesis $(5 \%)$, haematuria $(33.3 \%)$, bleeding gums $(11.7 \%)$, epistaxis $(1.7 \%)$, and haemoptysis $(3.3 \%)$ (Figure 1). Neurological involvement was seen in $26.7 \%$ cases (Figure 2). Ptosis (20\%) was the most common feature followed by altered sensorium $(15 \%)$, dysarthria $(8.3 \%)$, ophthalmoplegia $(8.3 \%)$, respiratory paralysis $(3.3 \%)$ and convulsions $(1.7 \%)$.
In the present study, vomiting and pain in abdomen were observed in $30 \%$ and $13.3 \%$ of cases respectively. Saini et al, in 1984 reported vomiting / pain in abdomen in 16\% of cases in his study in adults with snake bite ${ }^{11}$. The increase in symptoms could be due to smaller body mass of children leading to systemic envenomation or due to ingestion of herbal medicines.

In the present study, anaemia was observed in $41.7 \%$ and $11.7 \%$ of patients with vasculo-toxic and neurotoxic snake bites respectively. Leucocytosis was observed in $60 \%$ cases with relative neutrophilia in $63.3 \%$ cases. Most of the patients with leucocytosis $(46.7 \%)$ were of vasculotoxic snake bite (Table 2). Neutrophilia in snake bite signifies severe poisoning ${ }^{11}$. Thrombocytopenia was observed in $8.3 \%$ cases out of which $6.7 \%$ patients were of vasculo-toxic snake bite (Table 1). In our study acute renal failure was observed in $3.3 \%$ cases out of which two patients underwent haemodialysis and recovered.

WBCT 20 was positive in $86.4 \%$ of vasculo-toxic snake bites. According to the species of snakes, 
WBCT 20 was positive in $46.7 \%$ of viperine bites and was negative in all elapine snake bites (Table 4). The $p$ value was 0.0001 which is statistically highly significant. It means it is an important test to differentiate between viperine and elapine bites.

Bleeding time was prolonged in $13.3 \%$ cases out of which $11.7 \%$ patients were of vasculo-toxic snake bites; clotting time was prolonged in $56.7 \%$ cases of which all were of vasculo-toxic snake bites (Table 5). Similar coagulation disturbances $(58.6 \%)$ were observed by Kulkarni in $1994^{12}$.

Prothrombin time and activated partial thromboplastin time were prolonged in $36.7 \%$ and $33.3 \%$ cases respectively. Five of our patients with clinical and laboratory evidence of disseminated intravascular coagulation (DIC) had schistocytes and fragmented red blood cells on peripheral blood smear. All the cases showing features of DIC were bitten by vipers. These parameters normalised after administration of anti-snake venom.

All cases of snake bite were managed according to the national protoco ${ }^{13}$. In our study, $61.7 \%$ of cases received 1-10 vials, $36.7 \%$ cases $11-20$ vials and $1.7 \%$ cases $21-30$ vials of ASV. Hypersensitivity to anti-snake venom was observed in 6 patients, mild reactions like itching, urticarial, fever, vomiting were observed in all six cases while symptoms of systemic anaphylaxis like angioneurotic oedema, bronchospasm and hypotension were not seen in any of the cases. Supportive treatment with blood transfusion was given in all six cases.

There was a marked increase in clotting time after snake bite. In the present study the clotting time was $56.7 \%$ in snake bite cases. The prolongation of clotting time is very high in viper bite cases. This will help in the treatment by choosing monovalent anti-venom, since it is more effective than polyvalent anti-venom.

\section{Conclusions}

WBCT 20 is an important test to differentiate between viperine and elapine bites as it was positive in $46.7 \%$ of viperine bites and was negative in all elapine bites.

\section{References}

1. Ramakrishna CD, Kanattu PS. A study of cardiac profile in patients with snake envenomation and its complications. International Journal of Clinical Medicine 2017; 8(3): 167-77. https://doi.org/10.4236/ijcm.2017.83017

2. Modern Medical Toxicology: Organic Poisons (Toxins): Venomous Bites and
Stings. Available from: https://www.brainkart.com/article/Snakes--Organic-Poisons-(Toxins)_31042/

3. Utkin YN. Animal venom studies: Current benefits and future developments. World Journal of Biological Chemistry 2015; 6(2): 28-33.

https://doi.org/10.4331/wjbc.v6.i2.28

PMid: 26009701 PMCid: PMC4436903

4. Kandasamy S, Gopalakrishnan S, Venkatesan M, Ramakrishnan M. The clinical and biochemical profile of snakebite patients- A hospital based comparative study of envenomed and nonenvenomed victims, International Journal of Biochemistry and Biotechnology 2014; 3(2): 511-5.

5. Banerjee RN. Poisonous snakes of India, their venoms, symptomatology and treatment of envenomation. In: Ahuja MMS, ed. Progress in Clinical Medicine in India. Vol 2. New Delhi: ArnoldHeinemann Publishers (India), 1978: 13679.

6. Pahari S, Mackessy SP, Kini RM. Massasauga Rattlesnake (Sistrurus catenatus edwardsii): towards an understanding of venom composition among advanced snakes (Superfamily Colubroidea). BMC Molecular Biology 2007; 8: Article number: 115.

https://doi.org/10.1186/1471-2199-8-115

PMid: 18096037 PMCid: PMC2242803

7. Agarwal R, Aggarwal AN, Gupta D, Behera D, Jindal SK. Low dose of snake antivenom is as effective as high dose in patients with severe neurotoxic snake envenoming. Emergency Medicine Journal 2005; 22:397-9. https://doi.org/10.1136/emj.2004.020727 PMid: 15911942 PMCid: PMC1726801

8. Iwanaga S, Suzuki T. Enzymes in snake venom ; Handbook of Experimental Pharmacology book series (HEP, volume 52) pp 61-158, Available from: https://link.springer.com/chapter/10.1007 \%2F978-3-642-66913-2_4

9. Lewis RL, Gutmann L. Snake venoms and the neuromuscular junction. Seminars in Neurology 2004; 24(2):175-9. 
https://doi.org/10.1055/s-2004-830904

PMid: 15257514

10. Suri SRK, Kumar PJ. Platelet morphology, bleeding time \& clotting time in diabetic \& healthy females; Indian Journal of Applied Research 2018; 8(2):

11. Saini RK, Sharma S, Singh S, Pathania NS. Snake bite poisoning: a preliminary report. Journal of the Association of Physicians of India 1984; 32(2):195-7.
12. Kulkarni ML, Anees S. Snake venom poisoning: experience with 633 cases. Indian Pediatrics 1994; 31(10):1239-43.

13. Harris JB, Goonetilleke A. Animal poisons and the nervous system: What the neurologist needs to know Journal of Neurology Neurosurgery \& Psychiatry 2004; 75(3):

https://doi.org/10.1136/jnnp.2004.045724

PMid: 15316044 PMCid: PMC1765666 